Portland State University

PDXScholar

1978

\title{
The relationship of weight loss to self concept in the mentally retarded adult
}

Pauline Bunting Wall

Portland State University

Follow this and additional works at: https://pdxscholar.library.pdx.edu/open_access_etds

Part of the Psychiatric and Mental Health Commons, and the Psychology Commons Let us know how access to this document benefits you.

Recommended Citation

Wall, Pauline Bunting, "The relationship of weight loss to self concept in the mentally retarded adult" (1978). Dissertations and Theses. Paper 2838.

https://doi.org/10.15760/etd.2832

This Thesis is brought to you for free and open access. It has been accepted for inclusion in Dissertations and Theses by an authorized administrator of PDXScholar. Please contact us if we can make this document more accessible: pdxscholar@pdx.edu. 
AN ABSTRACT OF THE THESIS OF Pauline Bunting wall for the Master of Arts in Psychology presented May 23, 1978.

Title: The Relationship of Weight Loss to Self Concept in the Mentally Retarded Adult

APPROVED BY MEMBERS OF THE THESIS COMMITTEE:

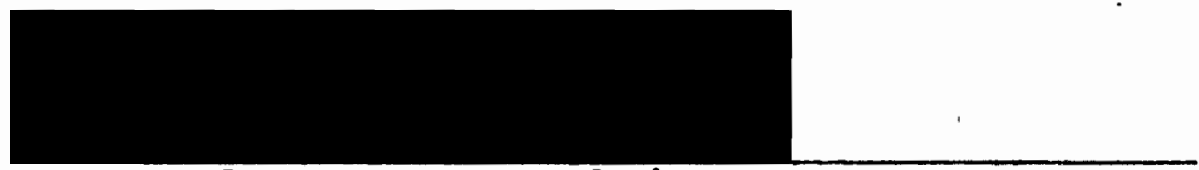

Pamela 0./Munter, Chairperson
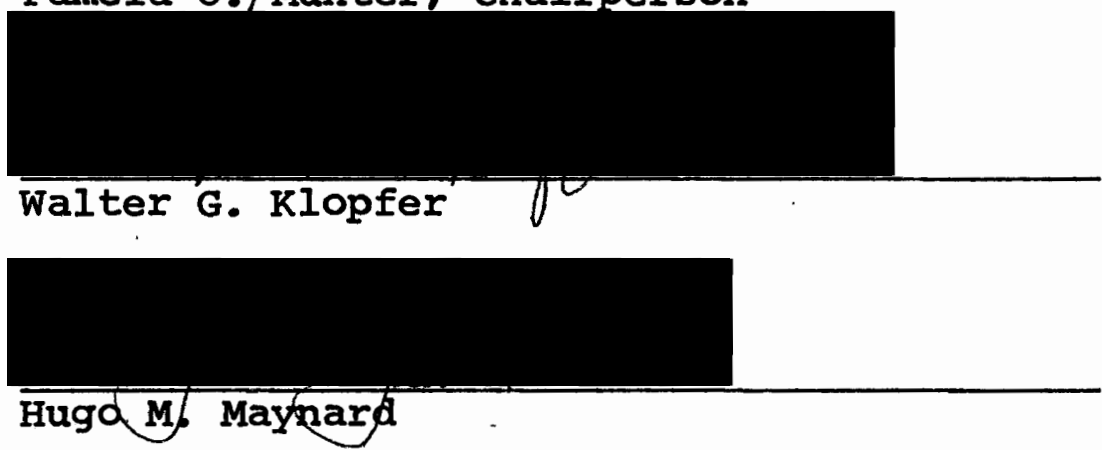

The major part of this study was a treatment program designed to motivate mentally retarded adults to lose weight within a small group setting. Subjects were tested pre- and posttreatment on the Tennessee Self concept scale to ascertain any improvement in self-esteem. A 50-question diet quiz was constructed by the experimenters and administered pre- and posttreatment to find out if the subjects would improve their knowledge of health and nutrition through the study.

The experiment took place at the Portland.Habilitation Center which is a sheltered workshop where mentally deficient adults are trained in social as well as work skills. of the subjects who were personally contacted, 28 agreed to take 
part in the ten-week program with 14 subjects being placed in the experimental group and 14 in the control group. The control group was treated as a social group, while the experimental group followed a didactic weight-losing program with various positive behavior modification techniques employed; such as, the fostering and using of group social pressure, gifts and applause for weight 1oss, and the posting of weight losers' names on a bulletin board at the center. While encouragement and camaraderie was the prevailing attitude, there was structure and seriousness about the process and the treatment.

The mean weight change in the experimental group was a weight loss of 4.96 pounds with a standard deviation of 3.19 pounds. The mean weight change in the control group was a gain of 2.42 pounds and a standard deviation of 7.20 pounds. The results of the study confirmed the first hypothesis in that the experimental subjects did actually lose more weight during the ten-week program than the control subjects. The second part of the hypothesis was also confirmed in that the experimental subjects gained more knowledge in nutrition and diet information than the control subjects.

Neither the experimental nor the control subjects showed a significant increase on any of the scales of the Tennessee self Concept scale: However, both groups increased their scores with the experimental group being +292 and the control group being +291 on the "Total Positive" scale, which was interpreted by the experimenters as implying that the group interaction, the attention, and the positive regard extended by the group facilitator and fostered in the other subjects had a positive effect in improving the feelings of self-worth in both of these groups.

It appears conclusive from the results of this study that mentally retarded individuals can be motivated to lose weight and that they can increase their knowledge about nutrition and health through this type of program. The study 
also gives weight to the notion that this special population can improve their self-esteem through the interaction of small groups.

It is the highest hope of those involved in this study that it will lend impetus to further studies and to an increased interest in psychotherapy with the mentally retarded population. 
THE RELATIONSHIP OF WEIGHT LOSS TO SELF CONCEPT IN THE

MENTALLY RETARDED ADULT

by

PAULINE BUNTING WALI

A thesis submitted in partial fulfillment of the requirements for the degree of

\author{
MASTER OF ARTS \\ in \\ PSYCHOLOGY
}

Portland State University

1978 
TO THE OFFICE OF GRADUATE STUDIES AND RESEARCH:

The members of the committee approve the thesis of Pauline Bunting Wall presented May 23, 1978.

Pamela 0. Munter, Chairperson

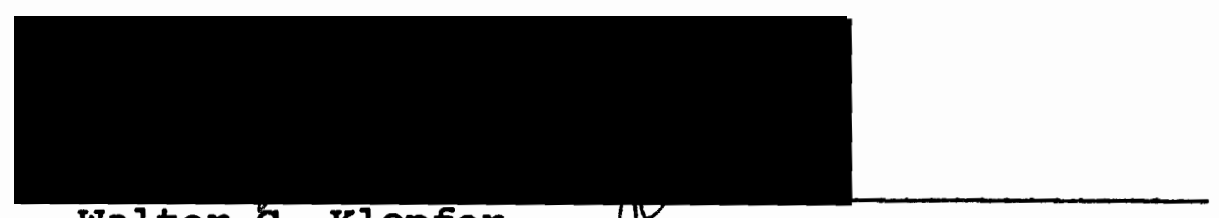

Walter G. Klopfer

jo

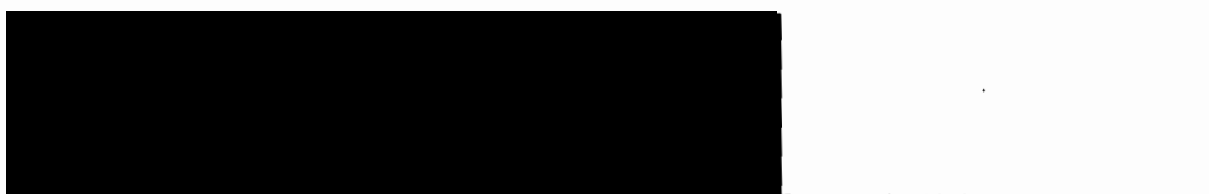

HugQ M. Maypara

APPROVED:

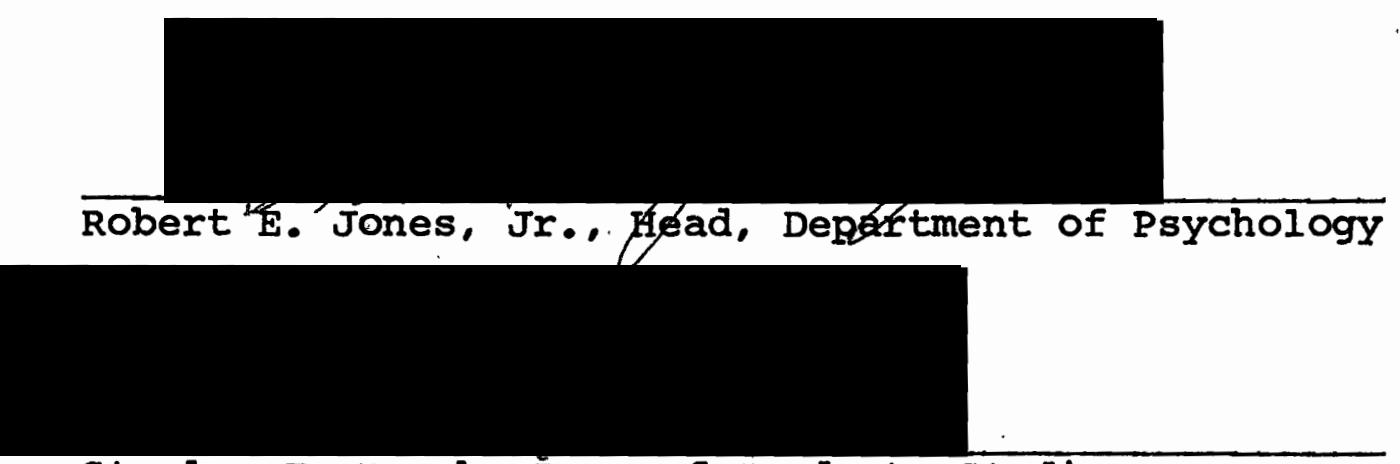

Stanley E. Rauch, Dean of Graduate studies 


\section{ACKNOWLEDGMENTS}

My sincere appreciation goes to my chairperson, Pamela 0. Munter, who has been not only my teacher and clinical supervisor, but also my friend and mentor. To walter G. Klopfer and Hugo M. Maynard go my thanks for their support and encouragement as well as for giving me the advantage of their excellent clinical and academic advice. While Barbara J. Stewart was not on my committee, she acted as my statistical advisor and was of inestimable assistance to me in the preparation of the statistics in the study. It was largely these four people whose contributions made this thesis the product of excellence which I believe it to be.

In addition, there is no way that I can fully express my appreciation and deep gratitude to my family, colleagues, and friends who were so very helpful, encouraging, and tolerant during those periods when it was necessary for me to center my priorities around this thesis project. 
ACKNOWLEDGEMENTS. . . . . . . . . . . . . iii LIST OF TABLES. • • • • • • • • • • • • • • • vi vi CHAPTER

I INTRODUCTION. . . . . . . . . . . I 1

II MENTAI RETARDATION. . . . . . . . 3

Historical Overview .......... . 3

Special Education ........... 4

Institutional Care. .......... 4

Intelligence Measured ......... 5

The Eugenic Movement....... $: 6$

Nazism. . . . . . . . . . . . . 7

The 1960's and Early 1970's ..... 7

Definition. . . . . . . . . . 9

Diagnosis and Classification. . . . . 9

Causes. . . . . . . . . . 10

Treatment ............. 10

Statistical Numbers . . . . . . . 11

Obesity Associated with Mental Retardation 11

Down's Synarome . . . . . . . . . II

Prader-Willi syndrome ........ 12

Hypopituitary Mental Defect ... . . 13

III WEIGHT LOSS AND DIET PROGRAMS . . . . . 15

Programs for Mentally Retarded Adults . . 15

Participatory-Observations of Programs. . 15

Programs for Non-Retarded Adults. . . . 16 


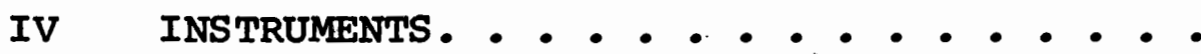

Tennessee Self Concept Scale . . . . Nutrition and Diet Quiz. . . . . . . 25

V PORTLAND HABILITATION CENTER • • • • • • 26

Work Training. . . . . . . . . . 26

Support Services . . . . . . . . 26

Counseling • • • • • • • • • • • 27

Physical Facilities. • . . . . . 28

VI METHOD • • • • • • • • • • • • • • 29

Subjects . . . . . . . . . . . 29

Procedure. . . . . . . . . . 30

Social Group (Control): $\cdot \cdot \cdot \cdot \cdot \cdot \cdot \cdot \quad 30$

Weight Control Group (Experimental) • • 31

VII RESULTS . • . • • • • • • • • • • • 36

Weight Change. . . . . . . . . 36

Experimental Group . . . . . . $\quad 36$

Control Group. . . . . . . . 36

Diet Quiz..... . . . . . . . . 40

Tennessee Self Concept Scale . . . . 42

VIII , DISCUSSION • • • • • • • • • • • . 45

IX CONCLUSIONS. - • • • • • • • • • • 50

BIBLIOGRAPHY • • • • • • • • • • • • • • •

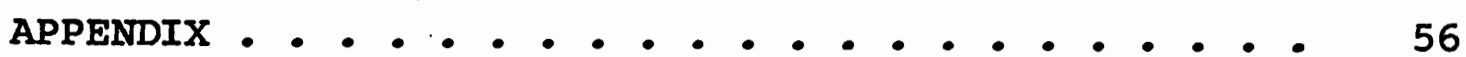




\section{IIST OF TABLES}

TABIE

PAGE

I Raw Scores on Age, IQ, and Weight for the Experimental Group. . . . . . .

II Raw Scores on Age, IQ, and Weight for the Control Group . . . . . . . . 38

III Anova Summary Table for conditions by

Trials Effects on Weight in Pounds. . Analysis of Variance Diet Quiz Summary Table . . . . . . . . . . . 40 Diet Quiz Score Changes. . . . . . . . Comparison of Experimental and control

Groups on Their Mean Pretest to Post Change on the Tennessee Self concept Scale's Ten Subscales . . . . . Changes on Tennessee Self Concept Scale "Total Positive" Scores . . . . . 
CHAPTER I

INTRODUCTION

Changes are being made in all segments of the population in order to integrate mentally retarded individuals into the nonretarded population. Mentally retarded individuals are being trained in special programs such as the one offered by the Portland Habilitation Center, Portland, Oregon, whereby they learn to operate machines, work in restaurants, do janitorial work, as well as other tasks. J. P. Edwards (1971) views the mentally retarded as courageous and well able to function in society and even working at risk-taking jobs. They ride the buses alone, live in group homes or apartments alone, socialize, handle money, get married, and even become independently functioning parents.

Iike the rest of the population, the mentally retarded also have individual problems that can be served through the services of various psychotherapeutical-type professions which includes that of the psychologist, psychiatrist, and social worker. They pay fees like the rest of the population and are entitled to quality services in return. It is sad to note that the president's Panel on Mental Retardation (1962) was severely critical of the psychological profession for the scant amount of research done on this particular segment of our population.

It would seem that the counselor or therapist serving this population should have special tools at his/her disposal. A weight control program as well as a study on the relationship of weight loss on self concept in the mentally retarded 
adult would be a step in that direction. Even with adults who have no physical and/or mental deficiencies, losing weight for the chronically obese individual is an almost insurmountable task. This problem is compounded for the person with a limited mental ability who usually has poor reasoning skills, few coping devices and a short attention span.

This study was conducted at the portland Habilitation Center which is a sheltered workshop institution where mentally deficient adults are trained in social as well as work skills. Their ultimate goal for each client is to provide them with the necessary skills to function in the community at large.

According to a survey taken as a part of this research project, 44 percent of the 85 clients in the work training program at the center are suffering from obesity ${ }^{l}$. These figures are in themselves evidence that there is an immediate and urgent need for the study and development of a weightlosing program specifically designed to assist the mentally retarded adult within the community.

As a result of this need, this study was devised. It was concerned with whether obese mentally retarded adults within the community could improve their self-concept, lose weight, learn good health habits, as well as whether traditional weight loss methods could be adapted to the mentally retarded in an effective manner. classes were held weekly or twice a week over a ten-week period with 14 control and 14 experimental subjects.

1. "Obesity" will be defined as body weight exceeding desirable weights' scale from Food and Your Health, U.S. Department of Agriculture (1969) by 10 percent or over. 


\section{CHAPTER II}

\section{MENTAI RETARDATION}

\section{Historical Overview}

The mentally handicapped in ancient Greece and Rome were treated as objects of scorn and persecution. Blind, deaf or mentally dull children were thrown into the Tiber River by their parents as a means of ridding themselves of a burden. The advent of Christianity which brought pity for the retarded gave way to indifference during the Middle Ages (Rosen, et al, 1976).

The mentally retarded served as fools and jesters in medieval times. They were regarded as "les enfants du bon Dieu" and could wander unmolested about the streets of Europe. They were regarded similarly by the American Indian, in the orient, and in certain writings such as confucius and the Koran. They were ignored by physicians as a medical responsibility, and there were no attempts made to educate them (Rosen, et al, 1976).

During the Reformation progress might have been expected, since there was a demand for feudal bondages and human suffering to end, but superstition was in full swing and both Luther and calvin denounced the mentally deficient as being "filled with Satan." Martinus Luther was said to have advised the Prince of Anhalt to take an obviously mentally deficient twelve-year-old child to the Moldau River and drown him. He stated that he had made the recommendation because in his opinion:

Such changelings were merely a mass of flesh, a massa carnis, with no soul. For it is in the Devil's power that he corrupts people who have reason and souls when he possesses them. The Devil sits in such changelings where their soul should have been (Kanner, 1964). 
The renaissance period came along and there was more concern in the area of humanitarianism and scientific study. It was in the Eighteenth Century that Descartes and others began the study of man (Rosen, et al, 1976).

Special Education. In 1801 a French physician, Jean Itard, to a school for deaf mutes discovered the historically famous "Wild Boy of Aveyron." He was reported to have been a naked child who ran from human beings and roamed the woods eating roots and acorns. He spoke no language and the sounds he made were inarticulate, drank water while lying flat on the ground, bit and scratched everyone who interfered with his actions, and was called among other things a natural savage. Itard felt that the boy's condition could be reversed and for five years tried unsuccessfully to prove this education theory. He finally gave up and victor, the wild boy, died in custodial care in 1828.

The French Academy of Science applauded Itard for the remarkable changes he had made in the boy. He could identify letters of the alphabet, understand the meanings of certain words, could recognize objects, and preferred the social life of civilization to an isolated existence in the wilds. The Academy felt that the pupil should be compared "only with himself," and the theory of special education was born (Kanner, 1964).

Institutional Care. As Itard is known as the originator of special education, Johann Guggenbuhl, born in 1816 in Switzerland, is acknowledged as the indisputable originator of the practice and the idea of institutional care for the mentally retarded person. He was a physician who studied cretinism which is a condition characterized by deformity with goiter, or the lack of a thyroid gland, and idiocy. With the financial assistance of a Swiss forester, Karl Kasthofer, he built a swiss institution for the care and the study of 
persons with cretinism. There was a central building with a large assembly hall, playrooms and bathing facilities. There was another building for training courses for attendants and teachers. He tried to awaken what he called the souls of his patients through habituation to regular routine, memory exercises, and speech training. His fame spread throughout the world and his work was recognized as a major reform.

He traveled extensively and acquired large amounts of money for his work. Through his efforts many other governments organized similar institutions. These institutions were often staffed by trainees from Guggenbuhl's institution. In time, however, because Guggenbuhl's methods did not show significant changes in his patients, many came to believe that feebleminded people could not be helped and he became known as a troublemaker. He was severely criticised by the same people who had previously praised him. It was not until after his death that the respect for his work was restored (Kanner, 1964). Great Britain, France, Germany, America, and almost all other civilized countries picked up on his idea for institutional care for those individuals who could not be cared for by their families or could not care for themselves. These included not only the mentally deficient but also those in extreme poverty, mental illness, blindness, senility, epilepsy, prostitution, and invalidism. By the 1880's, the trend was to provide long-term, large custodial facilities, which were intended to protect the mentally retarded person from the dangers and demands of society rather than to rehabilitate them (Kanner, 1964).

Intelligence Measured. The first formal scale for assessing intelligence of children was published in 1906 by Binet and simon. It was a test to differentiate normal from feeble-minded children and not to predict future intellectual intelligence. There were ten tests each about two minutes in 
length designed to measure "natural intelligence" rather than instruction. They defined intelligence as being judgement, good sense, and initiative. Length of lines were compared, digits repeated, sentences completed, questions comprehended, etc.

The Binet-Simon scale was revised in 1908 and the term "mental age" was first introduced. It was the age assigned to the child as the age level where not more than one test was failed. Terman's revision of 1916 standardized the procedures and this was the first use of the intelligence quotient, the ratio of mental age to chronological age (Rosen et al, 1976).

The Eugenic Movement. It was about the turn of the century that society began to feel that it needed some protection from the so-called "tainted" such as the criminal, mentally ill, and the mentally retarded. The Eugenic movement brought about a number of measures designed to limit the number of the retarded population (Kanner, 1964). These socalled "tainted" were segregated into institutions, sterilized on a mass scale, restrictions on marrying rights were frequently put into force, excluded from public schools, and other desperate attempts were made to "protect the human race from anticipated deterioration and degeneracy (Rosen et al. 1976) ."

Eugenics was a term coined by sir Francis Galton in 1883 advocating reducing the fertility rate of the unfit and citing heredity as an absolute causal factor, "the science which deals with all influences that improve the inborn qualities of a race." In 1874, a penologist by the name of Dugdale visited New York state prisons and thereafter made a genealogical survey based on the study of six persons who turned out to be blood relations of some sort. His survey was published in 1877 under the title, The Jukes, a study in Crime, Pauperism, Disease and Heredity. The family descended from two backwoodsmen who married two of five Juke (a fictitious name) sisters. Information on 709 of the descendants showed that 
140 had been imprisoned for crime, 280 were paupers, and most of them were of low physical and moral standards. There was no indication of any kind of intellectual assessments attempted. Dugdale asserted that, "not all feebleminded Jukes are criminal, but all the Juke criminals that I have known I regard as mentally defective . . (Kanner, 1964)." There were other geneological studies made which, for the sake of brevity, will not be covered here. These studies fanned the fire to the idea that mental deficiency was an inherited trait linked to criminality and/or other socially unacceptable behavior that could be and should be eradicated through sterilization and diminishing their numbers.

Further, mention is not made as to how the descendants were judged to be mentally defective. Since a scale for measuring intelligence had not been developed at that time, we must presume that the surveyors rated themselves as experts in this field but, in fact, were not. Furthermore, these reports did not take into account social/familial factors such as the lack of proper diets, isolation, learned behaviorisms, or the lack of educational stimuli, which would tend to bias reports and findings.

Nazism. The most terrible outcome of the Eugenic movement was carried out by Hitler's obsession with creating the "pure" race. Nazi Germany passed the Act for the Prevention of Hereditarily Diseased offspring in 1933. Physicians of the dreaded SS selected an estimated 100,000 individuals designated as mental defectives, physically deformed, and incurables for "mercy killings." There were few protests to this tragedy (Rosen et al, 1976).

The 1960's and Early 1970's. Two global wars had passed as had Korea and viet Nam. The civil rights movement had erupted into the violence at Selma, Newark, and watts. Women were asserting themselves openly as were the Chicanos, and 
consumers. Those who saw themselves as being deprived and oppressed also gained in militancy.

Parents of mentally retarded citizens banded together and formed the National Association for Retarded Children. As a result, retarded individuals of recent years through their parents, spokesmen, and advocates have and are continuing to win legal decisions designed to safeguard their basic human rights.

Courts have ordered institutions to improve conditions as well as return many residents to appropriate community habilitation settings. A federal district court (PennsyIvania Association for Retarded Children v. Commonwealth of Pennsylvania) declared in 1971 that mentally retarded children could not be denied a free public education. And the Supreme Court ruled that involuntary sterilization impinges on their rights (Robinson and Robinson, 1976).

Even though giant steps have been made during this era, mentally retarded citizens are still denied such fundamental rights as marriage, voting, and procreation. They are denied the right to marry in several states. The injustices still existing are evident by the proliferation of their legal advocacy groups; e.g., the "Conference on the Mentally Retarded Citizen and the Law" supporting equal rights in 1973, the "Declaration of General and Special Rights of the Mentally Retarded" issued in 1967 by the International League of Societies for the Mentally Handicapped, and others (Rosen et al.. 1976).

Enormous strides have been made in eliminating the "dehumanization" practices in institutions. Financial support through the Department of Health, Education and Welfare has been given in many areas. The vocational Rehabilitation laws have made their services available to the mentally handicapped as well as the physically handicapped (Rosen et al., 1976).

The greatest strides towards the improvement of the care and treatment for the mentally retarded have come since 
the 1960's. However, it is anticipated by many of their advocates as well as themselves that a great deal more can and will be done in the future to bring about humane treatment and care for them.

\section{Definition}

The DSM-II: Diagnostic and Statistical Manual of Mental Disorders prepared by The Committee on Nomenclature and Statistics of the American Psychiatric Association (1968), and which will hereafter be referred to as the DSM-II, has published the following widely accepted definition of this condition:

Mental retardation refers to subnormal general intellectual functioning which originates during the developmental period and is associated with impairment of either learning and social adjustment or maturation, or both...

\section{Diagnosis and Classification}

Diagnosis and classification of mental retardation is determined by intelligence quotient (IQ) tests. Following are the diagnostic classifications also published by DSM-II based on the Revised Stanford-Binet Tests of Intelligence, Forms $L$ and $M$ :

Borderline mental retardation-IQ 68-83

Mild mental retardation-IQ $52-67$

Moderate mental retardation-IQ $36-51$

Severe mental retardation-IQ 20-35

Profound mental retardation-IQ under 20

The DSM-II recognizes that the IQ should not be used as the only criterion for making a diagnosis as the adaptive behavioral capacity must also be considered. Social and emotional maturity, academic and vocational success, motor skills, and present functioning, along with developmental history, should also be taken into account.

Because he/she cannot learn or use as well as the average person what has been learned, the mentally retarded adult 
never reaches the ability level of normal adults. Their capacity for leading normal lives depends upon the degree of their retardation. Many retarded persons learn reading and writing skills of survival words on up to the level of our daily newspaper. They can take care of their personal needs and function as useful citizens in the working world by performing simple and repetitious tasks which are nontheless useful and of a productive nature.

\section{Causes}

There are more than 200 causes of mental retardation, but the reason can only be determined in 15 percent to 25 percent of the cases. Some of the more well-known causes are as follows:

1. Certain combinations of blood types in parents (RH Factor).

2. Syphilis occurring during pregnancy.

3. The mother having German measles during the first trimester of pregnancy.

4. Inherited conditions such as phenyleketonuria (PKU) whereby the body cannot use protein properly.

5. Metabolic disorders such as Galactosemia.

6. Genetic disorders such as Down's syndrome.

7. Brain damage occurring during a prolonged birth process when the baby does not receive enough oxygen.

8. Brain damage during childhood from illness or disease causing prolonged high fever.

9. Brain damage caused by head injury.

10. A lack of learning stimulation within the person's environment (Clarke and Clarke, 1974).

Treatment

As with all diseases and disorders, treatment of mental retardation varies according to its specific etiology. Contrary. to most diseases, it can rarely be reversed or cured by modern 
medicine. PKU, Galactosemia, Hereditary Fructose Intolerance, and Maple Syrup Urine Disease, to name a few, can be relieved through special medically prescribed diets which include specific additives (Robinson and Robinson, 1976).

Most methods of treatment are directed towards manipulating the environment in order to help the retardate function to the extent of their particular capacity.

Statistical Numbers

It is estimated that there are approximately $6,057,110$ retarded persons out of a population of 185,000,000 in the United States (Robinson and Robinson, 1976). This amounts to over three percent. There are no doubt many other persons in the general population who would fit into this classification but who have not been tested and diagnosed as such. This is a significantly large segment of the population to which special consideration should be given in devising methods by which they can best be served by those in the helping professions.

Obesity Associated with Mental Retardation

There are at least three clinically diagnosed types of mental retardation which demonstrate the occurrence of early childhood obesity. These diseases are Down's syndrome, Prader-Willi syndrome, and Hypopituitary Mental Defect. A brief description of these diseases will follow:

Down's Syndrome. Down's syndrome is by far the single most common chromosomal cause of severe to moderate mental retardation. One out of every 660 births is a Down's baby with the risk being considerably higher if the age of the mother is 35 years or older. Down's syndrome is often called "Mongolism" due to the epicanthal folds at the corner of the eyes, resulting in the "slanting eyes" similar to that of the Mongoloid people. Because the term carries 
negative connotations to many people, it has been discarded in favor of "Down's syndrome."

Down's syndrome is caused by a chromosomal anomaly. The autosomal chromosome normally occurs in pairs, one from the father and one from the mother. In 90 percent of the Down's syndrome cases, there is a third 21 chromosome. This is a result of faulty chromosomal distribution in the egg or sperm occurring before fertilization. This type of chromosomal aberration of Down's syndrome is called trisomy 21 (Robinson and Robinson, 1976).

The overall physical appearance of the individual with Down's is strikingly similar. The diminished brain development is the most serious effect. About 40 percent have a defect in the heart development. A few have gross malfunctioning of the lower large bowel and/or blockage of the upper intestinal tract. 'Similar characteristics include eyes that tend to slant upwards, skull size is small, and the neck is short and broad. Stature is shorter than average with the female being about four feet seven inches tall and the male being about five feet tall. Hypotonicity is prevalent at birth making the baby appear "floppy" and loose-jointed, and also having a prominent abdomen. While birthweight is normal to low, moderate to mild obesity frequently develops in childhood or adulthood, "requiring some supervision of eating habits (Robinson and Robinson, 1976)."

Carter (1965) states that the, "untreated mongoloid often is dysplastic, obese and unattractive," who is rarely accepted by the neighborhood in general. Carter also feels, however, that he/she can be attractive and accepted if well cared for by their family or guardians.

Prader-Willi syndrome. This syndrome was identified in 1965 by three German physicians, A. Prader, A. Labhart and H. Willi. They described the condition as, "a syndrome of obesity, hypogonadism, cryptorchidism, oligophrenia and 
hypotonia." The occurrence of the syndrome in first cousins has been confirmed in some cases. While the cause of the Prader-Willi syndrome is not known, it is believed by some physicians that it is due to a defect in the hypothalamic region. Hall and Smith (n.d.) list the criteria for inclusion in their studies at the oniversity of washington School of Medicine of 32 cases of people with this symarome as:

(1) hypotonia during infancy, (2) childhood onset of obesity, (3) characteristic facies, (4) hypogenitalism in the male, (5) small hands and feet, (6) short stature, and (7) mental deficiency.

Studies indicate that they are affectionate and happy until about three years of age. Changes appear from then on until the approximate age of five years with the characteristics of stubbornness and temper tantrums appearing. By the time they reach adulthood, serious personality problems have arisen. They are subject to extreme mood changes sometimes going into states of depression and other times performing sudden acts of violence and displays of temper with little or no reason. Intermittent periods are characterized by states of docileness and tranquility. Diets, hospitalization, and other measures have not been effective in curtailing the obesity in these individuals.

Hypopituitary Mental Defect. This condition is caused by a dysfunction of the pituitary gland and adjacent region of the brain. The most common type is the Frölich's syndrome or dystrophia adiposogenitalis. The characteristics of this syndrome consists of mild mental defect, severe under-developed genitalia and secondary sex characteristics, and obesity in the abdomens, hips and breast. pituitary dwarfism results from early impairment of the pituitary gland function alone but usually with no mental defect. The thyroid gland is usually found to be involved when mental defect is present. 
A very rare type of pituitary mental defect is the Iaurence-Moon syndrome. It is characterized by retarded sexual development, mental retardation, excessive height, and obesity. It is believed that genetic factors are the cause of this disease. Common traits shared by the LaurenceMoon people are shyness and seclusiveness.(DiMichael. n.d.). 
CHAPTER III

WEIGHT LOSS AND DIET PROGRAMS

Programs for Mentally Retarded Adults

A considerable amount of research on weight loss and diet programs for the mentally retarded adult in psychological abstracts, mentally retarded abstracts, exceptional child abstracts, dissertation abstracts, and sociological abstracts, revealed absolutely nothing except some few articles on behavior modification techniques utilized in controlling obesity in the institutionalized mentally retarded adult.

In only one instance was it found that such a program had been developed by any of the popular public institutions (Weight watchers). While this journal article was very enlightening and did offer encouragement that such a program could be successful, it was not specific about techniques employed, not quantitatively defined, and offered very few guidelines which could be followed (Morehouse, 1971).

There were 16 adults in the Weight watchers' program, ranging in age from 18 to 39, with the average intelligence quotient of the group being 46 . Only those nine individuals who actually lost weight were listed in the article. They had a weight loss ranging from 9.25 pounds to 55 pounds, with a total weight loss of 254.25 and a mean of 28.25.

\section{Participatory-Observation of Programs}

Based on the preceeding, it became apparent that new guidelines and rules for this program would have to be formulated. The logical manner, it was decided, in which this could be accomplished was through a participatory-observation schedule whereby the project director would join various 
weight-losing programs for the purpose of learning weightlosing techniques, as well as for the secondary gain of personally losing weight.

The weight-losing programs included: TOPS (Take off Pounds Sensibly), Weight Watchers, Overeaters Anonymous, Medical Diet Service, Weight Loss clinic, a small therapy group for overweight people at Tualatin Valley Guidance clinic, as well as weight loss group classes at Delauney Mental Health Clinic. Each program was attended for three weeks to two month sessions.

It was concluded from this observation project that the major motivator for weight loss adopted by most of these organizations was group support coupled with leader contact and the leader's positive regard for the client. Various behavior modification techniques were employed by all of the organizations. Only two of the organizations, Weight watchers and Medical Diet Service, placed strong emphasis upon sound nutritional training in conjunction with weight loss practices.

Losing weight for an improved appearance was, for the most part, the principal theme in most of the organizations. Losing weight for improved health and a longer life tended to be given low priority.

\section{Programs for Nonretarded Adults}

Whereas the literature revealed practically no studies on weight loss and diet programs for the mentally retarded population, there has been a plethora of studies and experiments conducted with the general population, who will be referred to as the nonretarded population for purposes of this study. A select number of these studies were reviewed in an effort to ascertain which program might be applied to mentally retarded individuals.

Stuart and Davis (1976) have written two informative books on the behavioral control of obesity. Many techniques of behavior modification in the control of obesity are 
described. The authors have included in their program the management of exercise, the management of food intake, and the behavioral control of eating. Strong emphasis is placed on the behavioral control of eating. They postulate three avenues toward the control of a "positive energy balance," which are:

1. Sharply reduce the consumption of energy as food.

2. Sharply increase the expenditure of energy as exercise.

3. Moderately decrease food intake while moderately increasing energy output.

Their general position is that the last alternative gives the greatest promise for long-term effects. They offer many behavior modification techniques in the control of obesity such as eating in one place, in one particular room, and not engaging in any other activity while eating. This is in order to avoid experiencing hunger in any environment in which a person has previously eaten or might eat in association with a particular activity where eating has been associated in the past.

This program also requires clients to keep a daily eating diary and recording food eaten, time, social (alone or with whom), where eaten, and mood when eaten. The diary is viewed as an awareness measure as well as a means of monitoring eating habits.

While much information was gleaned from this book, it was decided that the written food diary could not be used by the mentally retarded as most of those in this study would be illiterate. Also, as behavior modification techniques are routinely utilized at the center, it was felt desirable to deviate from this method as a means of avoiding boredom and apathy. Consequently, a more social, volunteer, and democratic program was sought. While various behavior modification methods were ultimately employed in the program, it was through the use of positive reinforcement during group 
meetings and not on a self-monitoring daily basis.

In his discussion on psychotherapy and obesity, stunkard (1976) - states that:

Most obese patients will not enter medical

treatment for obesity; of those who do, most will not lose a significant amount of weight; and of those who do lose weight, most will regain it . . Obesity is a chronic condition, resistant to treatment and prone to relapse.

stunkard further points out that information about diets is so widely available that the only people who go to see a physician are those who have failed on their own. Then those who fail from medical treatment ultimately reach mental health specialists. This would seem to make the job of the psychotherapist in assisting the obese to lose weight difficult, if not an impossible task.

It was early decided that only sound nutritional information would be used in the program. Meyer (1977) on writing about fads, fakes, and fallacies gives nine rules that can be used to enable individuals to spot fads and faddists. These rules were included and discussed during the group sessions with the experimental subjects. They are as follows:

1. Beware of any "magic" food. supplement that purports to solve all your health problems.

2. Only a faddist will promise to prevent or cure diseases that physicians generally regard as incurable.

3. If someone promises easy solutions (which may defy the laws of nature) to difficult problems, he or she is likely to be a faddist.

4. Faddists often recognize only one problem or only one factor in a complex problem at a time. (A study at Boston's Peter Bent Brigham Hospital showed that very low carbohydrate "reducing" diets do elevate blood cholesterol, even when one drinks plenty of water, but the faddists would have you believe otherwise).

5. Faddists frequently place great emphasis on blood sugar as an indicator of health and mental sanity or the absence thereof. 
6. Other faddists operate on the notion that if one is good, 100 must be 100 times better. (It can be harmful-fatally sol)

7. Faddists insist that all or most supermarket foods are devitalized, because they are deficient in, among other things, "trace minerals."

8. Faddists would like you to believe that additives are all bad, indeed, deadly.

9. Faddists would have you believe that anything "natural" is splendid for you and anything that is not is bad.

After an exhaustive search through the literature on weight losing programs for the nonretarded, it was decided that the method which could serve the most $S s$ in the least amount of time, as well as being adaptable to the mentally retarded population, was group therapy. Furthermore, the literature did not produce any information which might indicate that individual therapy was superior to group therapy.

Wollersheim (1970) did a study on the "Effectiveness of Group Therapy Based upon Learning Principles in the Treatment of Overweight women." Her study was conducted over a twelveweek (ten sessions) period from mid-october to mid-January and included four treatment plans which were identified as follows:

1. Positive Expectation-Social Pressure (Group SP)

2. Nonspecific Therapy (Group NS)

3. Focal Therapy (Group F)

4. No-Treatment-Wait-Control (Group C)

Positive Expectation-Social Pressure (SP). Wollersheim's (1970) study focused on fostering high positive expectations for losing weight. Also, to foster and use social pressure from group members to help ss reduce their weight. Therapist and members expressed mild negative reinforcers for weight gains along with encouragement to lose the next week. Weight losers were given much praise and encouragement. "Pig" tags were worn by weight-gainers (a technique which may be 
degrading and counter-productive to self-esteem, irrespective of whether the subjects ultimately lose weight or not); "turtle" tägs were worn by those who lost weight; and a "crown" was worn by the member who lost the most weight that week. Discussion about diets and specific ways to decrease overeating was avoided, but factual information concerning nutrition, obesity, and/or weight reduction was encouraged.

Nonspecific Therapy (NS). The first part of these sessions were the same as for the SP sessions-weigh-ins, etc. This was followed by 15-20 minutes of relaxation therapy. The remaining time was devoted to discussion about "the underlying causes for their behavior . . (Wollersheim, 1970.)"

Focal Therapy (F). As with the NS, the first part of these sessions were the same as for the SP sessions. This was followed with a discussion session to help identify learned eating practices, etc. Instrumental learning techniques were used extensively. The last part of the sessions were utilized to teach the subjects relaxation therapy.

No-Treatment-Wait-Control (C). This group was to provide control for such factors as intercurrent life experiences and environmental influences. Consequently, they received no treatment whatsoever.

The change from pretreatment to posttreatment in the SP groups was a 5.40 mean pound 10ss; 10.33 mean pounds lost for the F groups, NS had a 6.90 mean pounds 1ost; and the $\mathrm{C}$ groups had a mean pounds gain of 2.39.

clearly the Focal treatment was, according to this study, the most effective method. However, even though the $F$ and NS groups' weight loss was shown to be more effective than the SP group, it was felt that these types of treatment might not be as readily understood by the retarded population. 
Subsequent to this study, Wollersheim (1975) had four behavioral treatment manuals relative to the control of obesity published by the Journal Supplement Abstract Service of the American Psychological Association. This manual is similar to the treatment programs devised for the previously discussed study. The SP treatment program was referred to frequently by the experimenters in the present study. 
CHAPTER IV

INSTRUMENTS

\section{Tennessee Self Concept Scale}

The Tennessee Self Concept Scale (TSCS) is a Likerttype standardized scale used to measure self-esteem. It consists of 100 self descriptive statements which describes how an individual pictures him/herself. It can be used by persons 12 years of age and older and is usually selfadministering (Fitts, 1965). Due to the fact, however, that most of the subjects in this study cannot read, the statements were read to the $\mathrm{Ss}$ and the forms marked by the examiner. In order to avoid examiner bias, the tests were administered by examiners other than those people involved in this experiment.

The TSCS is available in two profiling and scoring systems, a clinical and research form and a counseling form. The counseling form was utilized in this experiment.

The TSCS was developed by Fitts (1965) to meet a need which would be "simple for the subject, widely applicable, well standardized, and multi-dimensional in its description of the self concept." Fitts felt that an individual's concept of him/herself is directly related to their general personality and state of mental health. Knowledge of this nature can be very helpful in helping an individual, as well as in making diagnostic assessments, behavioral science research, personnel selection, etc.

The Scale has been used in previous studies involving mentally retarded individuals. Collins et al (1970) made use of it in an experiment comparing self concepts of educable mentally retarded young people with nonretarded adolescents. This study showed that while the total positive score of the 
TSCS did not indicate a significant difference between the groups, there was a trend for the nonretarded subjects to have higher total positive scores. While the experimenters were not surprised to find the EMR adolescents as a group had negative self concepts, they were surprised to find that the nonretarded adolescents also had negative concepts and low self esteem.

The weight control classes in this study were conducted in group sessions. Mackeen and Herman (1974) used the TSCS to investigate the influence of group counseling on self esteem, anxiety, depression, and hostility in three groups of adult females. Results indicated a significant change in the level of self esteem in one group that had "no distracting crises to contend with." One might wonder at this point whether Mackeen and Herman consider being obese as a "distracting crises." The term was not operationally defined by them. They do, however, point out that a large number of the members in the two out of three groups which did not show a significant change in the level of self esteem were having marital problems, job problems, or newly divorced. They felt that the members of these groups "were not ready for selfconcept change if the newness of their situations caused them to perceive their environments as faulty rather than to perceive the need for change in themselves."

The preceeding are two studies in which the TSCS has been used to measure self concept in areas relevant to this experiment; namely; mental retardation and the effects of group counseling on self esteem.

The TSCS is a widely accepted instrument for measuring self concept. Buros (1974) lists 197 articles published in professional journals in which the TSCS was used to measure personality traits.

The 100 self-report items on the test produce scores on the following scales: 
1. Total Positive-the total measure of self esteem.

2. Self criticism-the capacity to criticize ones own self.

3. Identity-how the individual sees and, thereby, describes him/herself.

4. Self Satisfaction-the level of self acceptance.

5. Behavior-a measure of the individual's perception of how he/she functions.

6. Physical self-how the individual views his/her body, state of health, sexuality, and physical appearance.

7. Moral-Ethical Self-reflects feelings of moral worth, relationship to God, feelings of being a "bad" or "good" person.

8. Personal self-feelings of adequacy as a person apart from his/her body or relationship to others.

9. Family self-a person's feelings of value, worth, and adequacy as a family member.

10. Social Self-another "self as perceived in relation to others" category but is more generalized in its reference to "others."

Test-retest reliabilities over a two-week period on the above scales were from .60 to .92 with all but the Total and Row variability above .74. The standardization group ( $N=626$ ) on which norms were developed included equal numbers of both sexes, both Black and Caucasian subjects, as well as a wide range of socio-economic and education levels (Fitts, 1965).

To avoid any conflicting results which might arise from the way the test questions were interpreted by Ss due to having been administered orally instead of self-administered, an independent standardization of the test was made for this study. The test was administered to 20 college students of both sexes with various socio-economic backgrounds and age differences. The first ten students were given the test orally and the second ten students had it self-administered. Two weeks later it was readministered, but the method was reversed 
as a means of counter-balancing any possible effects caused by the order of administration. On all scales, the differences were negligible. Nontheless, T-tests were computed for the differences between means for each of the ten scales. On no scale was a significant difference found to exist.

It was, therefore, ascertained that there were no discernable differences evident in the test from being selfadministered as opposed to being administered orally, at least insofar as the previously described testing procedure was concerned.

Nutrition and Diet Quiz

This instrument was prepared specifically for this project and is based on the sound nutrition and diet information to be covered in the weight losing classes. The language and the quiestions have been prepared and presented in a simple and direct manner in order that they can be understood by a mentally retarded individual.

There are 50 true-false questions which were read to the subjects, with the replies being recorded on an answer sheet by the examiner. As with the Tennessee self concept scale, in order to avoid examiner bias, both the pre- and post-quizes were administered by a person other than one connected with this study. 


\section{CHAPTER V}

PORTLAND HABILITATION CENTER

The Executive Director, Robert Stuva, of the Portland Habilitation Center gave the Project Director of this study full cooperation in the implementation of this experiment. Since the study was conducted at the Center, an overview of its services to the clients as well as a brief description of its physical facilities will be covered.

\section{Work Training}

The major function of the Portland Habilitation Center is to provide comprehensive training in work skills for the mentally handicapped individual. Trainees spend an average of three to five days each week doing sub-contract work which has been solicited from industry. He/she learns about assembly-line type production, relating to supervisors, quotas, etc. The types of contracts the center receives include simple assembly-type packaging, fine motor dexterity, mail-outs such as folding papers and stuffing envelops, industrial machinery which includes heating and sealing polyethylene bags after filling them with a specific amount of nuts and bolts. A large on-going contract involves sterilizing and packaging headsets for $T V$ and radio listening for a major airline company (Stuva, 1977).

\section{Support Services}

In addition to work training, the Center offers other types of services which are referred to as "support services." The support services program is designed to help each client develop to his/her maximum level of independence. Training in practical living skills, job-seeking and placement, job skills, leisure time and socialization skills, are provided. 
Counseling and speech therapy services are also available.

\section{Counseling}

The Center maintains the services of a clinical psychologist as a consultant. This person performs psychotherapy as well as supervising the Center's regular counselor and practicum students from Portland State University. IQ, personality, vocational testing, and psychological assessments are only a few of the services offered by the counseling department. An eclectic approach to psychotherapeutic techniques is believed suitable for use with the mentally retarded by the counseling staff. In addition to having many of the same conflicts as the nonretarded population, they experience problems unique to their population. Some come from homes where they have been highly protected due to their retardation; others from living environments of extreme deprivation; while still others have spent their childhood and early adulthood in institutions. Role playing, relaxation therapy, catharsis, assertive training, behavior modification, Rogerian techniques, and Reality Therapy are (depending on the client's needs and level of retardation) as suitable for the retarded adult as they are for the nonretarded.

The psychotherapist frequently works with the staff in coordinating a treatment program for a particular client; e.g.. a client may be allowed a cup of coffee for good behavior, or a staff person may be asked to be more (or less) verbally firm depending on a client's emotional tolerance of firm responses.

Group therapy as well as individual therapy is offered by the Counseling Department. Group therapy is particularly beneficial in helping the clients improve their self-concept and human relationships. Some clients are overly withdrawn and shy, others are aggressive and defensive, and still others exhibit institutionally learned behaviorisms. The group members help each other help themselves by sharing experiences 
and feelings with each other.

Physical Facilities

The Portland Habilitation Center is located at 3829

S.E. 74th Avenue, Portland, Oregon. The facilities are modern in design, spacious, well lighted, and ventilated, with large windows which tend to make the classrooms and work areas cheerful and bright. The Center's grounds are spacious with grass, shrubs, trees, and picnic tables much like a well kept park area.

It would appear that a major effort has been put forth to deinstitutionalize the appearance of the facility. The landscaping is pleasing to the eye and relaxing; the furnishings are modern and colorful; and contemporary art work hangs in the hallways.

It is in this setting which this experiment has been conducted. 
CHAPTER VI

METHOD

Subjects

Subjects were personally contacted by the project Director at the Portland Habilitation Center and asked if they would like to participate in a weight control group program for a period of ten weeks., The project Director was already familiar with their weights as all clients at the Center had been weighed recently and pounds over ideal weight calculated for each client. Those clients who answered affirmatively were included in the study.

All of the subjects met the following requirements:

1. Body weight at least ten percent over ideal weight according to the U.S. Department of Agriculture's scale from "Food and Your Health."

2. Diagnosed as mentally retarded with a Full Scale Intelligence Quotient of 83 or less on the Weschler Adult Intelligence scale.

3. No severe psychological problems, or history of same.

4. Willing to invest a total of ten weeks in the program.

The subjects were rank ordered by number of pounds over ideal body weight and evenly distributed with every other subject being placed in the experimental group and the other subjects going into the control group. Subjects who were to be placed in the control group were told that the weight losing group was filled, but that there was a social group being formed and that they could be a member of that group if they wished. None of the control subjects declined to be in the newly formed social group.

The ten-week sessions were broken down into weekly 
meetings for the first two weeks in order to allow the subjects to adjust to the procedure without pressure. This was followed by six twice-a-week sessions in order to intensify and motivate the experimental subjects towards weight 1oss. The last two sessions were weekly meetings in order to give the subjects time to taper off emotionally from the process of group and therapist dependencies. Each meeting for both groups lasted for 45 to 50 minutes.

\section{Procedure}

Social Group (Control). Rather than have a control group in which the subjects would receive no treatment, a social group was formed. This was done in order to allow for the effects on self-esteem which might be derived from group interaction and experimenter's attention rather than actual weight loss in the experimental group. Control subjects were treated with the same positive regard as the experimental subjects. No formal format was followed, but discussion about losing weight was not presented by the experimenter. Control subjects did not during the ten-week sessions elect to discuss their excess poundage, so that it was not necessary to divert the group's attention away from any weight control discussions as had been anticipated. Following is a schedule and differentiation of individual sessions:

Session Week Discussion procedure

$1 \quad 1$ Subjects were weighed and weights recorded by facilitator. They were told that this was for the Center's information and did not object to same. Subjects were advised that this would be a general discussion and social group. It tended to be a getting acquainted period with no specific topic covered. They were asked to return the next week at the same time and location.

22 Drugs and drinking problems within the community were discussed.

33 Topic of conversation revolved around house cleaning and how each client helps out at home. 
Session Week Discussion procedure (Continued)

43 More discussion on house cleaning.

54 Group talked about families and living situations. Some of them live with their parents while others live in group homes or apartments.

64 Each member told whether he/she has brothers or sisters and how many. Also talked about what they like or dislike in the respective siblings.

75 Discussion was about TV programs and whether it is good or bad for children to watch violent programs.

85 Subjects talked about the kind of music that each one liked.

96 Members talked about Christmas decorations at the Center and how they had participated in the preparation of the decorations.

106 Concern was expressed about the heavy rains and flooding in portland and other parts of the country.

117 Talked about what a perfect staff person would be. All members felt that one or more of the clients at the Center should be employed as a staff person.

127 More discussion about the perfect staff person.

138 Christmas vacation was topic for today. Most of the subjects are staying home or visiting relatives who reside close to their home.

148 Discussed what everyone received for Christmas. Most of the subjects were given tapes, records, and/or clothes.

159 Topic of discussion was influenza and colds, and what should be done when a person is ill. clients were told that next week marked the end of our group meetings as the ten weeks would be over.

1610 Subjects were informed that this would be the last group meeting. While they expressed some unhappiness about the group terminating, a sense of silliness seemed to prevail. Knockknock jokes were told and there was much laughter and camaraderie. They were also weighed and weights recorded by examiner.

Weight Control Group (Experimental). The principle methods used in motivating the experimental ss to lose weight 
was that of fostering in the subjects high positive expectations for losing weight; the fostering and using of group social pressure; behavior modification techniques in the form of gifts for weight loss as well as applause; and the imparting of sound nutritional information. It should be noted, also, that the subjects were treated at all times with respect and a high positive regard. No form of negative reinforcement was used during this experiment. Encouragement and camaraderie was the prevailing attitude and mode of treatment. This is not to say, however, that there was not structure and seriousness about the process and the treatment. The subjects committed themselves to the program by agreeing to be in it, and the examiner encouraged them in that direction during each session.

Following is the schedule and format which was followed for each meeting:

1. Upon coming to the meeting room, subjects were weighed and weights recorded by the facilitator. During the weigh-in period, the facilitator always expressed pleasure at a weight-loss or encouragement for losing the following week to those who gained weight or stayed the same.

2. After the weigh-ins, each subject and the facilitator would take his/her seat in a circle of chairs. The facilitator would read from the weight schedule each subject's name and the amount of weight loss, after which facilitator and subjects would applaud and express approval. Subjects who gained or stayed the same received encouragement for losing the following week.

3. The two subjects who lost the most weight since the last meeting were told by the facilitator to take their seats at the head of the circle. Subjects who were already in those chairs relinquished them good-naturedly.

4. The two subjects who lost the most weight since the last meeting were then rewarded with a gift by the facilitator. It was always gift-wrapped. Gifts were in the form of cologne, necklaces, bubble bath, soap-on- 
a-rope, and other similar items. Subjects were encouraged to show their gifts to the other members in the group and experience pride in their accomplishment of losing weight.

5. A short discussion period followed in which some clients would talk about the problems they might be having in following through with good weight losing principles. other clients and facilitator encouraged them and offered some advice for handling their particular problems. It should be noted, however, that at no time were specific diets offered by either the facilitator or any of the subjects.

Differentiation of individual sessions:

Session Week Individual Program

1

This was a getting acquainted meeting. Most of the session was spent in getting organized. The facilitator reminded the subjects that this was a weight control group and that they would be encouraged to lose weight for their good health, as well as for appearance reasons. Facilitator further advised that there would be prizes each week for those who lost the most weight and that their names would be posted on the bulletin board in the hall at the Center.

22 Facilitator read questions 1 through 10 on the Diet Quiz which was used for this study, and the subjects answered in unison "true or false." After each question was answered, a short discussion about it followed. By answering in unison, those subjects who knew the answer to the question were reinforced by the facilitator's approving head nod, and those who did not know the answer were not embarrassed by their lack of knowledge.

3 Diet questions 11 through 20 with same procedure. 3 Diet questions 21 through 30 with same procedure. 4 Diet questions 31 through 40 with same procedure. 4 Diet questions 41 through 50 with same procedure.

75 The instruction part of this session had to do with the advantages of exercise. Each subject did an exercise after which the group members applauded. Facilitator pointed out the advantages of exercise in improving health, helping in weight loss, and firming up the muscles. 
Session Week Individual Program (Continued)

8

9

10

12

13

15
117 Subjects were shown pictures of different kinds 148 Diet questions 21 through 30; same as Session 4. 1610 Diet questions 41 through 50; same as Session 6.

5

Exercise program was continued with each of the subjects doing an individual exercise and the other members clapping their hands to express approval.

6 Facilitator read the Meyer (1977) rules on how to spot fads and faddists which are listed on pages 18-19 of this study. Subjects told of their own experiences in this regard and discouraged the other subjects who were contemplating using fad type methods of dieting.

6 Luncheons and snacks were discussed today. Subjects were encouraged to have fruit instead of candy. Subjects told what they had for lunch and other subjects applauded for those members who had nutritious and well-balanced lunches. of food items and asked to pick out "good" and "bad" food items as well as proper proportions. This was done as a joint project with all members participating at the same time.

27 Diet questions 1 through 10; same as session 2.

38 Diet questions 11 through 20 ; same as session 3. 159 Diet questions 31 through 40; same as Session 5. Subjects were also told that this was the end of our weight control program, but were encouraged to continue with good weight-losing principles.

7. After the more didactic individual program, the subjects would rise from their seats, form a circle, hold hands and sing the following lyric which was taken from the TOPS program:

The more we get together, together, together. The more we get together, the thinner we'll be. For your loss is my loss, and my loss is your loss. The more we get together, the thinner we'll be.

Facilitator would then say, "One more time," or words to that effect. Subjects would sing the 
song again but this time with much more zeal. This tended to promote group togetherness and camaraderie, as well as relieve anxieties for those who were uneasy.

7. The group was dismissed and the facilitator made an attempt to make eye contact or to speak approvingly to each member in parting.

8. Names of the two clients who lost the most weight for each session and the number of pounds lost was posted on a brightly colored 12 by 14 inch poster in the hall at the Center as a means of promoting pride in their weight loss accomplishment and motivation for continued weight-losing practices.

Non-verbal as well as verbal messages were viewed as very important methods of imparting information to the subjects. Eye contact, warmth, and a relaxed body posture were all seen as methods of relaying the message of total acceptance of each subject and a belief in their ability to lose weight. 
CHAPTER VII

\section{RESULTS}

Of the 28 subjects who began the study, two dropped out and are not included in any of the calculations. One of the subjects who dropped out was in the experimental group and one was in the control group. This left 13 subjects in each of the two groups to complete the ten-week program.

\section{Weight Change}

Experimental Group. The mean weight change in the experimental group was a weight 1 oss of 4.96 pounds with a standard deviation of 3.19 pounds.

Table $I$ shows the subjects in the experimental group and associated weight changes as well as ages, sex, and intelligence quotients. Ideal weights represent the midpoints of ideal weight ranges from "Food and Your Health" published by the U.S. Department of Agriculture (1969)

There were seven females and six males; the age range was 20 to 36 years with a mean of 25.23; Full scale IQ on the Weschler Adult Intelligence Scale ranged from 47 to 67 with a mean of 57.38 .

Control Group. The mean weight change in the control group was a gain of 2.42 pounds with a standard deviation of 7.20 pounds.

There were eight females and five males; ages ranged from 20 to 31 years with a mean of 24.08; the IQ range was 40 to 70 with a mean of 56.31 .

Subjects in the control group along with associated weight changes, ages, sex and intelligence quotients are listed in Table II. 
TABLE I

RAW SCORES ON AGE, IQ, AND WEIGHT

FOR THE EXPERIMENTAL GROUP

\begin{tabular}{|c|c|c|c|c|c|c|c|c|}
\hline $\begin{array}{l}\text { Experi- } \\
\text { mental } \\
\text { Subjects }\end{array}$ & Age & Sex I & .Q. $\mathrm{W}$ & $\begin{array}{l}\text { Starting } \\
\text { Weight }\end{array}$ & $\begin{array}{l}\text { Ideal } \\
\text { Weight }\end{array}$ & $\begin{array}{l}\text { Pounds } \\
\text { Over } \\
\text { Ideal } \\
\text { Weight } \\
\end{array}$ & $\begin{array}{l}\text { Ending } \\
\text { Weight } 0 \\
\end{array}$ & $\begin{array}{l}\text { Net } \\
\text { Changes }\end{array}$ \\
\hline$s_{1}$ & 24 & $\mathbf{F}$ & 55 & 249 & 112 & 137 & 243 & -6 \\
\hline$s_{2}$ & 22 & $\mathbf{M}$ & 67 & 242 & 142 & 100 & 231 & -11 \\
\hline$s_{3}$ & 36 & $\mathbf{M}$ & 55 & 261 & 163 & 98 & 254 & -7 \\
\hline$s_{4}$ & 20 & $\mathbf{M}$ & 61 & 237 & 151 & 86 & 235 & -2 \\
\hline$s_{5}$ & 23 & $\mathbf{F}$ & 47 & 212 & 129 & 83 & 209 & -3 \\
\hline$s_{6}$ & 22 & $\mathbf{F}$ & 58 & 174 & 112 & 62 & 172.5 & .5 \\
\hline$s_{7}$ & 22 & $\mathbf{M}$ & 51 & 215 & 155 & 60 & 213 & -7 \\
\hline$s_{8}$ & 30 & $\mathbf{M}$ & 49 & 157 & 105 & 52 & 157 & 0.0 \\
\hline$s_{9}$ & 20 & $\mathbf{F}$ & 64 & 155.5 & 109 & 46.5 & 151.5 & -4 \\
\hline $\mathrm{s}_{10}$ & 29 & $\mathbf{M}$ & 64 & 188 & 142 & 46 & 182.5 & $-\quad 5.5$ \\
\hline$s_{11}$ & 23 & F & 59 & 153 & 112 & 41 & 144 & -9 \\
\hline$s_{12}$ & 23 & $\mathbf{F}$ & 55 & 138 & 100 & 38 & 134 & -4 \\
\hline$s_{13}$ & 35 & $\mathbf{F}$ & 61 & 137 & 112 & 25 & 131.5 & -5.5 \\
\hline$s_{14}$ & 35 & $\mathbf{M}$ & 33 & 154 & 129 & 25 & $x \times x \times x$ & $X \times X X X X$ \\
\hline \multicolumn{2}{|c|}{$\begin{array}{l}\text { Weight Change } \\
M=-4.962 \\
S D=3.185\end{array}$} & \multicolumn{2}{|c|}{ Range 0.0} & \multicolumn{2}{|l|}{ to -11} & \multicolumn{2}{|c|}{$\begin{array}{l}\text { I.Q. Range } 47 \\
M=57.3846\end{array}$} & to 67 \\
\hline \multicolumn{4}{|c|}{$\begin{array}{l}\text { Age Range } 20 \text { to } 36 \\
M=25.2308\end{array}$} & . & & \multicolumn{2}{|c|}{$\begin{array}{l}\text { Females-n }=7 \\
\text { Males } n=6\end{array}$} & 7 \\
\hline
\end{tabular}

*Subject dropped out of the study prior to completion and will not be included in the computations. 
TABLE II

RAW SCORES ON AGE, IQ, AND WEIGHT

FOR THE CONTROL GROUP

Pounds

Over

Control

Starting Ideal Ideal Ending Net

Subjects Age Sex I.Q. Weight Weight Weight Weight Changes

\begin{tabular}{|c|c|c|c|c|c|c|c|c|}
\hline$s_{15}$ & 22 & $F$ & 70 & 204 & 97 & 107 & 217 & +13 \\
\hline$s_{16}$ & 22 & $\mathbf{M}$ & 49 & 251 & 151 & 100 & 256.5 & +5.5 \\
\hline$s_{17}$ & 22 & $\mathbf{F}$ & 68 & 195 & 106 & 89 & 209 & +14 \\
\hline$s_{18}$ & 31 & $F$ & 69 & 213 & 132 & 81 & 214 & -1 \\
\hline$s_{19}$ & 25 & $\mathbf{F}$ & 42 & 175 & 97 & 78 & 162 & -13 \\
\hline$S_{20}$ & 28 & $\mathbf{M}$ & 62 & 199 & 137 & 62 & 202 & \\
\hline$S_{21}$ & 26 & $F$ & 40 & 164 & 106 & 58 & 165 & +1 \\
\hline $\mathrm{s}_{22}$ & 29 & $F$ & 48 & 152 & 109 & 43 & 149 & -3 \\
\hline$S_{23}$ & 22 & $\mathbf{M}$ & 65 & 214 & 171 & 43 & 224.5 & +10 \\
\hline$s_{24}$ & 20 & $\mathbf{M}$ & 40 & 139 & 100 & 39 & 138.5 & - \\
\hline$s_{2}$ & 22 & $\mathbf{F}$ & 60 & 159 & 125 & 34 & 161 & +2 \\
\hline${ }^{{ }^{S}} S_{26}$ & 21 & $\mathbf{F}$ & 46 & 165 & 132 & 33 & $\mathrm{XXXXX}$ & $\mathrm{XXXXXX}$ \\
\hline$S_{27}$ & 23 & $\mathbf{F}$ & 52 & 137 & 112 & 25 & 137 & 0.0 \\
\hline$s_{28}$ & 21 & $\mathbf{M}$ & 67 & 153 & 129 & 24 & 153 & 0.0 \\
\hline
\end{tabular}

Weight Change Range +14 to -13

$M=+2.423$

I.Q. Range 40 to 70

$M=56.3077$

$S D=7.202$

Age Range 20 to 36

$M=24.0769$

Females-n $=8$

Males- $n=5$

*Subject dropped out of the study prior to completion and will not be included in the computations. 
The subjects were rank ordered according to pounds over ideal weight and every other subject was placed in either the experimental or control condition.

A $2 \times 2$ analysis of variance was performed to determine if there was a significant treatment effect across trials on the dependent variable of weight in pounds. The summary of this ANOVA is presented in Table III.

\section{TABLE III}

ANOVA SUMMARY TABLE FOR CONDITIONS

BY TRIALS EFFECTS ON WEIGHT IN POUNDS

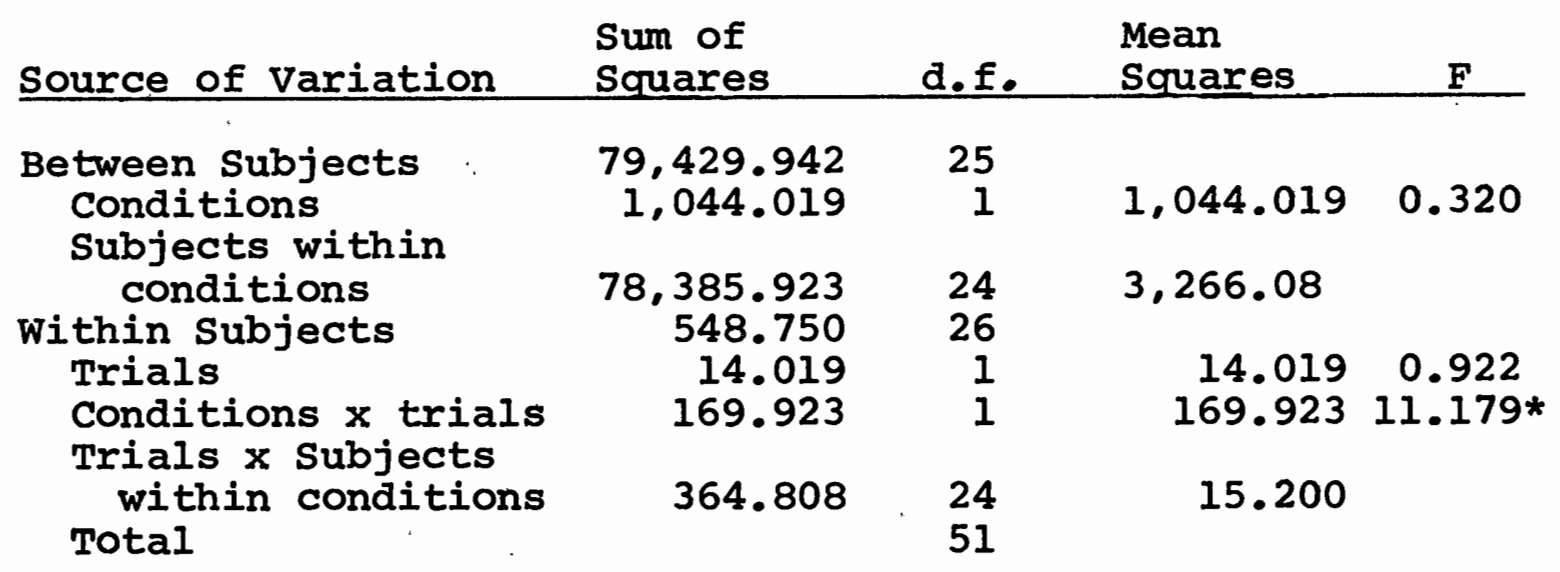

$$
* p<.01
$$

Results of the ANOVA indicated that neither the main effects due to conditions nor the main effects due to trials was significant at the .05 level. The significant ( $p<.01$ ) conditions $x$ trials interaction was followed by tests for simple main effects.

Comparing the mean weights before and after treatment for each of the conditions separately revealed that there was a significant decrease in weight for the experimental group $\left(t_{(24)}=3.043, p<.005\right)$.

The increase in weight for the control group, however, did not reach statistical significance $\left(t_{(24)}=-1.685\right.$, $\mathrm{p}(.10)$. 
Diet Quiz

A $2 \times 2$ analysis of variance was also performed on the diet quiz to examine the effects of the two conditions across pre- and posttest trials. This analysis summary is presented in Table IV.

TABLE IV

ANALYSIS OF VARIANCE

DIET QUIZ SUMMARY TABLE

\begin{tabular}{lrrrr} 
Source of Variation & $\begin{array}{l}\text { Sum of } \\
\text { Squares }\end{array}$ & d.f. & $\begin{array}{l}\text { Mean } \\
\text { Squares }\end{array}$ & F \\
\hline Between Subjects & $1,121.558$ & 25 & & \\
$\quad$ Conditions & 81.250 & 1 & 81.250 & 1.874 \\
$\quad \begin{aligned} \text { Subjects within } \\
\quad \text { conditions }\end{aligned}$ & $1,040.308$ & 24 & 43.346 & \\
Within Subjects & 474.500 & 26 & & \\
$\quad$ Trials & 166.327 & 1 & 166.327 & $14.025 *$ \\
Conditions x trials & 23.558 & 1 & 23.558 & 1.986 \\
$\quad$ Trials x Subjects & & & \\
$\quad$ within groups & 284.615 & 24 & 11.859 & \\
Total & $1,596.058$ & 51 & &
\end{tabular}

$$
* p<.005
$$

Results of the ANOVA indicated that the main effects due to trials were significant beyond the .005 level. There was no evidence for significant main effects due to conditions.

Tests for simple main effect, comparing the group means before and after treatment for each of the conditions separately, revealed that there was a significant increase in test scores for the experimental group $\left(t_{(24)}=-3.645\right.$, $\mathrm{p}<.005)$.

The increase in scores for the control group did not attain statistical significance $\left(t_{(24)}=-1.652, p<.10\right)$. 


\section{TABLE V \\ DIET QUIZ \\ SCORE CHANGES}

Experimental

Pre- Post- Net

Subject Test Test Change

$S_{1}$

$3440+6$

$\mathrm{S}_{2}$

$\mathrm{S}_{3}$

$\mathrm{s}_{4}$

$\mathrm{S}_{5}$

$s_{6}$

$\mathrm{S}_{7}$

$\mathrm{s}_{8}$

$\mathrm{S}_{9}$

$\mathrm{S}_{10}$

$\mathrm{S}_{11}$

$\mathrm{S}_{12}$

$\mathrm{S}_{13}$

$* \mathrm{~S}_{14}$
$33 \quad 39+6$

31

35

$25 \quad 39+14$

$25 \quad 37+12$

$35 \quad 33-2$

$40 \quad 40$

0.0

$3739+2$

$4145+4$

32

$43+11$

33

$34+1$

$4041+1$

$35 \quad \mathrm{XX} \quad \mathrm{XXXXXX}$

Control

Pre- Post- Net

Subject Test Test Change

$\mathrm{S}_{15}$

39

$44+5$

$\mathrm{S}_{16}$

$28 \quad 37+9$

$\mathrm{S}_{17}$

45

43

$-2$

$\mathrm{s}_{18}$

32

36

$+4$

$\mathrm{S}_{19}$

37

39

$+2$

$\mathrm{S}_{20}$

29

$27-2$

$\mathrm{S}_{21}$

$28 \quad 35+7$

$\mathrm{S}_{22}$

28

$24-4$

$\mathrm{S}_{23}$

$\mathrm{S}_{24}$

$\mathrm{S}_{25}$

${ }^{*} \mathrm{~S}_{26}$

$34 \quad 34$

0.0

$\mathrm{S}_{27}$

$33 \mathrm{xx} \quad \mathrm{xxxxxx}$

$\mathrm{S}_{28}$

33

35

$+2$

35

42

$+7$

TOTALS

$+64$

$+33$

$M=4.923$

$S D=5.545$

$M=2.539$

$\mathrm{SD}=4.294$

*Subjects dropped out of the study prior to completion and will not be included in the computations. 
Tennessee Self Concept Scale

Change scores (posttest minus pretest) were computed for each subject for each subscale on the. Tennessee Self concept scale and for the Total positive scale.

T-tests (one-tailed) were used to determine if the experimental group had a greater mean increase from pretest to posttest than the control group on the TSCS's "Total positive" and nine subscales. Individual scores and changes on the Total positive scale are listed on Table VII for both the Experimental and Control groups. Results of the t-tests are shown in Table VI.

TABLE VI

COMPARISON OF EXPERIMENTAL AND CONTROL GROUPS ON THEIR MEAN PRETEST TO POST CHANGE ON THE

TENNESSEE SELF CONCEPT SCALE'S TEN SUBSCALES

Total Positive

Self-criticism

Identity

Self-satisfaction

Behavior

Physical Self

Moral-Ethical Self

Personal Self

Family Self

social self $t=0.008 \mathrm{~ns}$

$t=-1.026 \mathrm{~ns}$

$t=0.446 \mathrm{~ns}$

$t=-0.140 \mathrm{~ns}$

$t=0.050 \mathrm{~ns}$

$\mathrm{t}=-0.505 \mathrm{~ns}$

$t=-0.111 \mathrm{~ns}$

$t=0.923 \mathrm{~ns}$

$t=0.735 \mathrm{~ns}$

$t=0.541 \mathrm{~ns}$

As can readily be seen, there was no significant difference between the mean increase for the two conditions on any of the scales.

In the interest of brevity and because of its apparent insignificance, a table for the individual nine subscales has not been included in the study. 


\section{TABLE VII}

CHANGES ON

TENNESSEE SELF CONCEPT SCALE

"TOTAL POSITIVE" SCORES

\section{Experimental}

Pre- Post- Net

Subject Test Test Change

$\begin{array}{lll}\mathrm{S}_{1} & 342 & 361+19\end{array}$

$\mathrm{S}_{2}$

$\mathrm{S}_{3}$

$\mathrm{S}_{4}$

$\mathrm{S}_{5}$

$s_{6}$

s.

$\mathrm{s}_{8}$

$\mathrm{S}_{9}$

$\mathrm{S}_{10}$

$\mathrm{s}_{11}$

$\mathrm{S}_{12}$

$\mathrm{S}_{13}$

${ }^{*} \mathrm{~S}_{14}$
$330341+11$

$\begin{array}{lll}331 & 327-4\end{array}$

$247309+62$

$309 \quad 289-20$

$318320+2$

$269329+60$

$\begin{array}{lll}321 & 312-9\end{array}$

$372364-8$

$265324+59$

$333383+50$

$318356+38$

$321353+32$

$309 \mathrm{XXX} \mathrm{XXXX}$
Control

Pre- Post- Net Subject Test Test Change

$\mathrm{S}_{15}$

$\mathrm{s}_{16}$

$352389+37$

$\mathrm{s}_{17}$

$292 \quad 324+32$

$\mathrm{s}_{18}$

$\mathrm{S}_{19}$

$\mathrm{S}_{20}$

$\mathrm{S}_{21}$

$\mathrm{S}_{22}$

$\mathrm{S}_{23}$

$\mathrm{S}_{24}$

$\mathrm{S}_{25}$

${ }^{*} \mathrm{~S}_{26}$

$\mathrm{S}_{27}$

$\mathrm{S}_{28}$

$\overline{+292}$
$382420+38$

$298293-5$

$334337+3$

$297332+35$

$303 \quad 333+30$

$314335+21$

$354383+29$

$265286+21$

$267282+15$

$292 \mathrm{XXX} \quad \mathrm{XXXX}$

$292328+36$

$321 \quad 320-1$
TOTALS

$$
\begin{aligned}
& M=22.462 \\
& S D=29.413
\end{aligned}
$$

$\overline{+291}$

$M=22.385$

$S D=15.075$

*Subjects dropped out of the study and are not included in the computations. 
Relationship of Weight Change to IQ

Nutritional Knowledge and Self-Concept

To determine the relationships between weight loss or gain and IQ, and between weight change and change in both nutritional knowledge and self-concept, Pearson productmoment correlation coefficients were computed.

\section{Weight Loss or Gain and IQ}

$$
\begin{array}{lll}
\text { Experimental } & r=-0.40 \quad\left(t_{(11)}=-1.447, \mathrm{~ns}\right) \\
\text { Control } & r=0.61 \quad\left(t_{(11)}=2.553, p<.05\right)
\end{array}
$$

Higher IQ subjects were inclined to gain more weight in the control group, and showed a tendency to lose more weight in the experimental group, though only the former relationship is statistically significant.

Weight Loss or Gain and Change in Diet Quiz Scores.

$\begin{array}{lll}\text { Experimental } & r=-0.14 & \text { ns } \\ \text { Control } & r=-0.09 & \text { ns }\end{array}$

Neither of these correlation coefficients is significantly different from zero.

Weight Loss or Gain and TSCS "Total Positive" Change. Experimental $r=-0.28 \mathrm{~ns}$ Control $\quad r=0.65 \quad\left(t_{(11)}=2.837, p<.05\right)$

There is a significant relationship ( $p<.05)$ between weight gain and increase in the Tennessee Self concept Scale scores for the control group.

The slight tendency for experimental subjects who lost more weight to increase their self-concept on the Tennessee Self Concept scale is not significant. 
CHAPTER VIII

\section{DISCUSSION}

The present study originated out of a concern for the large number of mentally retarded clients at a sheltered work shop who were obese. These individuals were informally viewed by members of the staff and the Counseling Department as being lower in self-esteem than other mentally retarded clients at the Center, giving weight to the notion that there was a relationship between obesity and self-concept.

As a result of the preceding, it was hypothesized that the experimental subjects in this study would lose more weight, gain more knowledge in nutrition and diet information, and show a greater degree of improvement in their selfconcepts as measured by the Tennessee Self Concept Scale, than the control subjects.

The guidelines for launching a weight control program specifically for the mentally retarded were practically nil due to the extreme lack of study done by the psychological profession or other helping professions with this particular segment of the population. After an exhaustive and unrewarding search of the literature, it was decided that a modified program designed for the nonretarded population would have to be utilized. Consequently, the wollersheim (1975) weight losing program entitled, "Obesity: Behavioral Treatment Manuals," published by the Journal Supplement Abstract Service of the American Psychological Association, was modified to fit the needs and level of comprehension by retarded adults and incorporated into this study.

The results of the study confirmed the first hypothesis in that the experimental subjects did actually lose more weight during the ten-week program than the control subjects. 
This was the major focus of the study and the statistics revealed highly significant results at the .005 level. It could be generalized with a high degree of confidence that weight losing groups with mentally retarded adults utilizing the same methodology could expect similar results. With the experimental group showing a mean weight loss of 4.96 pounds, the weight change range was zero to -11. All of the experimental subjects in the study consistently maintained or lost weight and the standard deviation of 3.19 pounds revealed fairly consistent variability in weight loss among the individuals.

In contrast, the control group had a mean weight gain of 2.42 pounds with a standard deviation of 7.20 pounds. The range was +14 to -13 pounds. This increase in weight did not reveal statistical significance. It is interesting to note that the standard deviation of 7.20 pounds revealed a much wider variability than the experimental group's 3.19 pounds. The range for the controls went from an extreme weight gain of 14 pounds to an extreme weight loss of 13 pounds. This can be accounted for by the influence of the program on the experimental subjects in that they were consistently motivated to lose weight, whereas no such consistent motivation existed for all of the subjects in the control program. This also points out the apparent lack of self-control which these individuals have over good health and weight control principles, as well as the need for implementation and continuance of similar programs for all mentally retarded persons within our present society.

The second part of the hypothesis was also confirmed in that the experimental subjects did gain more knowledge in nutrition and diet information than the control subjects. There was a significant increase in test scores for the experimental subjects at the .005 level of significance. This is viewed as conclusive evidence that similar programs could teach this population better health habits, and that they can 
learn effectively through this type of program.

While the increase in scores for the control group did not attain significant results, it should be noted that their knowledge about health and diet did show an increase. It is believed that this can be accounted for by the enthusiastic relaying of good health and diet information from the experimental subjects to their peers. However, even with the increased knowledge about diet, the control subjects continued along the path to more weight gains. This would seem to show that the obese mentally retarded population is similar to the obese nonmentally retarded population in that even though the nonretarded are aware of good health and diet information, there is an alarmingly high incidence of obesity in this country (stunkard, 1976).

Neither the experimental nor the control subjects showed a significant increase on any of the scales of the Tennessee Self Concept scale. However, both groups increased their scores with the "Total positive" scale for the experimental group being +292 and the "Total Positive" scale for the control group being +291 . This would seem to imply that the group interaction, the attention, and the positive regard extended by the group facilitator and fostered in the other subjects had a positive effect in improving the feelings of self-worth in both of these groups.

The correlational study revealed a significant relationship between IQ and weight loss or gain. Higher IQ subjects in the experimental group lost more weight than the lower IQ subjects, and even though the results were not significant, there was a notable trend. Higher IQ subjects in the control group gained more weight than the lower IQ subjects and revealed significant results at the .05 level, showing that there was one chance out of 20 that this was due to chance factors.

As these subjects are similar in age and living situations, it seems very probable that the reasons for the 
weight gains and losses can largely be attributed to the subjects with the higher IQ's having more control over their exercise and eating habits, whereas the opposite is true of the lower IQ individuals. As a result of this information, it might also be predicted that a higher rate of success using this type of program might be expected with subjects of higher mental ability than those of low ability. A better program for all ability levels within the mentally retarded range could possibly be one which would include parental and/or guardian participation.

Weight loss or gain and nutritional knowledge was also subjected to a correlational study revealing no significant difference in either the experimental or the control group. This would tend to imply that even though weight losses and gains were taking place that it did not correlate significantly with diet and nutritional information which the subjects had learned. This further confirms the notion that even though these individuals increased their knowledge about good health and diet habits, they did not lose or gain weight as a result of having acquired this knowledge. It seems reasonable to conclude that the weight loss was due to the motivating factors presented in the group classes; whereas the weight gains were due to a lack of such motivating factors related to weight 1oss, and the continuing practice of weight-gaining habits existing within the subjects of the control group.

The correlational study done on the relationship of weight change to self-concept yielded surprising results. There was a slight tendency for the experimental subjects who lost more weight to increase their self-concept, but the control subjects actually showed a significant relationship between weight change and increased self-concept at the .05 level. These results might be considered as spurious even though it was at a high level of significance due to the extreme range of weight changes that took place within the control group $(+14$ to -13$)$. With such a small sample size, 
the correlation is more affected by such extreme scores inasmuch as it shows a linear relationship. 
The results of this study confirmed the hypothesis that mentally retarded adults within the community can be motivated to lose weight as well as improve their knowledge about good health and diet habits. The small group method employing different avenues of positive reinforcement, the fostering of weight loss expectations, and positive regard towards the subjects on the part of the facilitator have been shown to be highly effective in bringing about weight loss and better health knowledge. It can be predicted with a high degree of confidence that replication of this type of program will result in a similar degree of success. It is, therefore, hoped that individuals in the mental health professions who might have the opportunity to work with this special population will employ this program in assisting them not only towards losing excess weight but towards better health habits as well.

Both the control subjects and the experimental subjects showed an improvement in their self-concept from the pre- to posttreatment scores on the tennessee self concept scale, and even though it was not significant there was a trend. Since the only single change of routine habits known by the experimenters to have occurred in these people's lives during the ten weeks that the experiment was being conducted were the group meetings, it infers that the improvement in self-concept was based on the effects of these meetings on the subjects. This gives rise to the notion that the mentally retarded can benefit from this type of interaction, and it is recommended as a means of therapy for the improvement of self-esteem as well as other emotional problems. 
The correlation between weight gains and losses and higher IQs was attributed to the individuals with higher IQs having more control over their eating and exercise habits, and thereby benefiting more directly from motivating techniques employed than the lower IQ individuals. Consequently other persons who might replicate this experiment should take this into consideration. A program for lower IQ individuals should no doubt be one that includes the participation or cooperation of the subjects' parents and/or guardians; and, furthermore, their participation might also contribute to the success of a program for higher ability subjects.

It appears conclusive from the results of this study that mentally retarded adults within the community have a high potential for benefiting from the services of psychologists or individuals in the helping professions. Losing weight even for the nonretarded population is a very difficult task, yet the experimental subjects in this study showed highly significant results for weight loss, which came about as the result of a program using such simple techniques as encouragement, high expectations for weight loss, small gifts, respect, and positive regard towards the subjects.

The potential for the mentally retarded population to improve their self-esteem through the use of group therapy is apparent from the improvement in self-esteem noted in both the experimental and the control group subjects. The experimenters of this study found a large number of these individuals not only to be receptive and in need of therapy to improve their self-esteem but to be almost starved for even the smallest amount of therapeutic assistance. With this in mind, it is the highest hope of those involved in this study that it will lend impetus to further studies and to an increased interest in psychotherapy with the mentally retarded population.

Great strides have been made towards the improvement and care of this special population since the 1960's, but the psychological profession is lagging far behind. A great deal 
can be done to bring about and to make available programs specifically designed to improve the mental and emotional well-being of the mentally retarded individual within the community:

- . whatever difference there is between the mentally retarded and other children, there is one respect in which they are all the same-they can be taught, they can be helped, they can lead normal lives, contributing to the society instead of burdening it-if we will it.

If we are prepared to accept responsibility for these children to work with them-not to what we think is the limit of their abilities, but to the limit of our abilities-they can be helped.

Robert F. Kennedy

Address to the Rhode Island

Association for Retarded Children April 24, 1965 


\section{BIBLIOGRAPHY}

Balch, Philip, and A. William Ross. "A Behaviorally Oriented Didactic-Group Treatment of Obesity: An Exploratory Group," Journal of Behavior Therapy \& Experimental Psychiatry. 1974, 5, pp. 239-343.

Bruno, Frank J. Think Yourself Thin: How Psychology Can Help You Lose Weight. New York: Harper \& Row, 1974.

Buros, Oscar Krisen. Tests in Print II: An Index to Tests, Test Reviews, and the Literature on specific Tests. Highland Park: The Gryphon Press, 1974.

Carter, Charles H. Medical Aspects of Mental Retardation. Springfield: Charles C. Thomas, 1965.

Clarke, Ann M.., and Clarke, A. D. B. Mental Deficiency; The Changing Outlook. New York The Free Press, 1974.

Collins, Hardin A., et al. "Self-Concept of EMR and Nonretarded Adolescents," American Journal of Mental Deficiency. 1970, 75, pp. 285-289.

Committee on Nomenclature and Statistics of the American Psychiatric Association, The. DSM-II: Diagnostic and Statistical Manual of Mental Disorders. Washington, D.C.: American Psychiatric Association, 1968.

DiMichael, Salvatore G. "Medical Aspects of Mental Deficiency," Vocational Rehabilitation of the Mentally Retarded. Washington, D.C.: U.S. Government Printing Office, Rehabilitation Service Series No. 123, n.d.

Edwards, Jean P. "Concept Normalization." Portland, Oregon. Non-published article, 1971.

Fitts, W. H. Tennessee Self Concept Scale, Manual. Nashville, Tennessee: Counselor Recordings and Tests, 1965.

Hagen, Richard I. "Group Therapy Versus Bibliotherapy in Weight Reduction," Behavior Therapy. 1974, 5, pp. 222-234.

Hall, Bryan D., and David W. Smith. "Prader-Willi syndrome," Dysmorphology Unit, Department of Pediatrics. Seattle: University of Washington School of Medicine, n.d.

Kanner, Leo. A History of the Care and Study of the Mentally Retarded. Springfield: Charles C. Thomas, 1964.

Kessler, Sheila. "Treatment of Overweight," Journal of Counseling psychology. 1974, 21, pp. 395-398.

Kiell, Norman. The Psychology of obesity. Springfield, Ill.: Charles C. Thomas, 1973. 
Leland, Henry, and Daniel E. Smith. Mental Retardation: Present and Future Perspectives. Worthington: Charles A. Jones Publishing Company, 1974.

Mackeen, Beverly A., and Al Herman. "Effects of Group Counseling on Self-Esteem," Journal of counseling Psychology. 1974, 21, pp. 210-214.

Mahoney, Michael J., and Kathryn Mahoney. Permanent Weight Control: A Total Solution to the Dieter's Dilemma. New York: W. W. Norton \& Company, Inc., 1976.

Mahoney, Michael J.. et al. "Relative Efficacy of selfReward, Self-Punishment, and Self-Monitoring Techniques for Weight Loss," Journal of Consulting and Clinical Psychology. 1973, 40, pp. 404-407.

Mayer, Jean. A Diet for Living. New York: Pocket Books, 1977.

"Mental Retardation;" World Book Encyclopedia, The. Chicago: Field Enterprises Educational Corporation, 1977.

Morehouse, Rebecca. "You Can Do It: The Story of Mentally Retarded Young People Who are Losing Weight, "Weight Watchers. New York: Weight Watchers Magazine, 1971.

Pennwalt. Are You Really Serious About Losing Weight? n.a., U.S.A.: Pennwalt Prescription Products, 1974.

Penick, Sydnor B... et al. "Behavior Modification in the Treatment of Obesity," Psychosomatic Medicine, 1971, 33, pp. 49-55.

President's Panel on Mental Retardation. A Proposed Program for National Action to Combat Mental Retardation. Washington, D.C.: U.S. Government Printing Office, 1962 .

Robinson, Halbert B., and Nancy M. Robinson. The Mentally Retarded Child: A Psychological Approach. New York: McGraw-Hill Book Company, 1976.

Rosen, et al. The History of Mental Retardation: Collected Papers. Volumes I and II. Baltimore: University Park Press, 1976.

Snow, David L.., and Mark I. Held. "Group Psychotherapy With Obese Adolescent Females," Adolescence. 1973, 8, pp. 407-414.

Stuart, Richard B... and Barbara Davis. Slim Chance in a Fat World: Behavioral Control of obesity. Chicago: Research Press, 1976.

Stunkard, Albert J. The Pain of obesity. Palo Alto: BulI Publishing Co.; 1976. 
Stuva, Robert, Executive Director, Portland Habilitation Center. Personal Interview, 1977.

williams, Sue Rodwell williams. Nutrition and Diet Therapy. Saint Louis: The C. V. Mosby Company, 1977.

Wollersheim, Janet P. "Effectiveness of Group Therapy Based Upon Learning Principles in the Treatment of Overweight Women," Journal of Abnormal Psychology. 1970, 76, pp. $462-474$.

Wollersheim, Janet P. "Obesity: Behavioral Treatment Manuals," Journal Supplement Abstract Service of the American

Psychological Association. Washington, D.C.: American Psychological Association, 1975. 
NUTRITION AND DIET QUIZ

True

or

False

1. Most weight problems are inherited. T $\underline{F}$

2. People who are overweight are considered "obese." $\underline{T}$ F

3. Dieting and increased exercise is a good way to reduce. $\quad \underline{T} F$

4. People on reducing diets should eliminate all

fats and carbohydrates from their diets.

$\mathbf{T} \quad \underline{\mathbf{F}}$

5. A person is well-nourished if he/she eats the right kinds of foods.

T $\mathbf{F}$

6. Water is not fattening. $T$ F

7. Good nutrition helps to make a person feel well. T F

8. A person can lose weight by eating less food. $\underline{T}$

9. Skipping breakfast is a good way to lose weight. $T$ F

10. A person should eat four different kinds of food each day.

11. People on a reducing diet should cut all fat from their meat.

12. A good breakfast for most people might be a cup of orange juice, an egg, toast and coffee. I F

13. People need vitamin pills to ensure good health. $T$ F

14. The grapefruit and meat diet is a good nutritional way to lose weight.

15. People on a reducing diet should eat lots of peanut butter and nuts.

16. It is good for people on a reducing diet to fry their meat.

17. Skim milk is just as fattening as whole milk. T $\underline{F}$

18. Walking is good exercise. $\underline{T} \mathbf{F}$ 
19. A healthy way to reduce is to eat three nutritious meals a day.

I $\mathbf{F}$

20. Milk should be included in a weight-reducing diet.

I $F$

21. Fish and chicken aid reducing.

T $F$

22. Wheat bread is more nutritious than white bread. I F

23. Fruit and vegetable juices contain more calories than most soda pops.

T $\quad \mathbf{E}$

24. The amount of food a person needs depends upon his/her age, sex, and activities.

I $F$

25. A good diet should include breads and cereals; milk products; meat, fish or eggs; fruit and vegetables.

T $F$

26. Overweight people are healthier than skinny people.

T $\quad \mathbf{E}$

27. No single food supplies all the nutrients we need.

$\underline{\mathbf{T}}$

28. Everyone should take vitamins in order to be well nourished.

$\mathbf{T} \quad \mathbf{F}$

29. Hamburger is just as nourishing as steak.

T $\mathrm{F}$

30. People eating the same meals will show the same signs of poor or good nutrition.

T $\mathrm{F}$

31. It is a sign of good health for people to get heavier as they grow older.

T $\quad$ E

32. Tab has more calories than coca cola.

T $\mathbf{E}$

33. Good eating habits are important to health. I F

34. It is a good idea to exercise every day. I F

35. A good nutritional practice is to eat a variety of foods each day.

I $\mathbf{F}$

36. Soda pop is good for young children.

T $\quad \mathbf{E}$

37. No reducing diet should contain potatoes or bread. 
38. Alcohol contains many empty calories.

39. Most overweight adults and children cannot control their weight.

T $\quad \underline{E}$

40. People on a reducing diet should eat a dish of ice cream in the evening.

$\mathbf{T} \quad \underline{\mathbf{F}}$

41. An apple or an orange is a healthier snack than a candy bar.

42. Healthy and active people require some sweets in their diet each day in order to meet their energy needs.

43. A cheese sandwich, carrot sticks and celery, milk, and a fresh peach would be a good nutritious lunch.

44. The four kinds of food we all need each day are: milk; meat or eggs; vegetables and fruits; bread or cereal.

45. People should drink several glasses of water each day.

46. There are no calories in coffee or tea.

47. All people should put lots of salt on their food. $T$ F

48. A person who has been obese or overweight since they were a child is probably "naturally fat."

$\mathbf{T} \quad \underline{\mathbf{F}}$

49. Exercising makes a person hungrier so it is not a good way to reduce.

50. Drugs can be very helpful in reducing. 